\title{
Establishment of cell lines from adenocarcinomas of the esophagus and gastric cardia growing in vivo and in vitro
}

Received: 7 September 2000 / Accepted: 31 October 2000 / Published online: 20 February 2001

(C) Springer-Verlag 2001

\begin{abstract}
The aim of this study was to establish cell lines of adenocarcinomas of the gastro-esophageal junction(GEJ), which grow in vivo and in vitro. Primary esophageal and gastric cardia adenocarcinomas and corresponding lymph node metastases were xenografted subcutaneously to immunodeficient nude mice. In addition, tumor tissue was also used for in vitro culture. Xenografting of 70 primary adenocarcinomas and 17 metastases resulted in the initial growth of 22 and 6 tumors, respectively (total 32\%). Upon retransplantation, six long-term xenografts [esophageal adenocarcinoma (OAC)P33X, OACP47X, OACP56X, OACP58X, OACP67X, OACP76X] from primary tumors and three (OACM2.1X, OACM30X, OACM53X) from metastases were obtained. In vitro culture attempts of 34 primary tumors and nine metastases resulted in the establishment of three $(7 \%)$ permanent in vitro growing cell lines. From one patient, a cell line from the primary tumor (OACP4 C) and from a lymph node metastasis (OACM4.1 C) was established. The third cell line (OACM5.1 C) was also derived from a lymph node metastasis. The in vivo and in vitro cell lines were characterized using immunocytochemistry and microsatellite analysis to verify their epithelial and human tumor origin, respectively.
\end{abstract}

Keywords Adenocarcinoma - Esophagus - Xenograft . Tumor cell line $\cdot$ In vivo $\cdot$ In vitro

\footnotetext{
N.J. de Both · H.F.B.M. Sleddens · W.N.M. Dinjens ( The Rotterdam Esophageal Tumor Study Group, Department of Pathology, Josephine Nefkens Institute, Erasmus University Medical Center Rotterdam (EMCR), Rotterdam, The Netherlands e-mail: dinjens@path.fgg.eur.nl Tel.: +31-10-4088389, Fax: +31-10-4089487

B.P.L. Wijnhoven · H.W. Tilanus

The Rotterdam Esophageal Tumor Study Group, Department of Surgery,

Erasmus University Medical Center Rotterdam (EMCR), P.O. Box 1738, 3000 DR Rotterdam, The Netherlands
}

\section{Introduction}

Despite the rising incidence of adenocarcinomas of the gastro-esophageal junction (GEJ), little is known about the cellular and molecular mechanisms underlying the origin of these tumors. This is partly caused by the lack of sufficient in vivo and in vitro model systems. Tumor xenografts are useful models for studying the in vivo behavior of tumors. Furthermore, human tumor xenografts are a source of tumor cells without an admixture of normal human cells. This facilitates the analysis of tumor cell-specific molecular alterations, e.g., loss of heterozygosity $(\mathrm{LOH})$.

Until now, only a limited number of GEJ adenocarcinoma xenografts have been reported in the literature [3, 10]. Also, only a few in vitro human GEJ adenocarcinoma cell lines have been established $[1,9]$. In this study, we report the generation of 28 xenografts and three cell lines growing in vitro obtained from primary GEJ adenocarcinomas and lymph node metastases. From these xenografts, nine permanent in vivo growing tumor lines were obtained.

\section{Materials and methods}

Xenografting and in vitro culture

The surgical resection specimens were placed on ice shortly after removal. Small tissue fragments were taken from the most vital parts of the primary tumor and lymph node metastases and were used for subcutaneous xenografting or tissue culture. Xenografting was performed by subcutaneous implantation of two to six small tumor fragments in female nude NMRI mice (6-8 weeks of age). When growing tumors reached a size of about $5 \mathrm{~mm}$ in diameter (between 2-4 months), the tumors were removed and small parts were used for retransplantation.

For tissue culture, a piece of tissue from the primary tumor or metastasis was rinsed in sterile Hanks balanced salt solution, supplemented with penicillin and streptomycin, and cut into small pieces with sterile scissors and forceps. The tissue fragments were transferred to five to ten petri dishes, to which RPMI-1640 (BioWhittakker, Verviers, Belgium) was added as culture fluid. This was supplemented with $10 \%$ fetal calf serum and antibiotics. No 
growth factors or other additives were used. After 1 week of culture, the growth of cells could be observed along the edges of some fragments. Initially, fibroblasts also started growing but, after a number of passages, they stopped growing, whereas the tumor cells became adapted to the growth medium and started to divide more rapidly. Cultures were passaged by trypsinization and, after a number of passages, in vitro the cell lines were used for transplantation to nude mice to verify their tumorigenic nature. Cultured cells were trysinized and, after washing with tissue culture medium and phosphate buffered saline (PBS), suspended in PBS in a concentration of $50 \times 10^{6}$ cells $/ \mathrm{ml}$. From this suspension $5 \times 10^{6}$ cells $(0.1 \mathrm{ml})$ were injected subcutaneously into a nude mouse.

\section{Histology and immunocytochemistry}

Primary tumors, metastases, and xenografts were routinely fixed in $10 \%$ buffered formalin and embedded in paraffin. Sections (5- $\mu \mathrm{m}$ thick) were routinely stained with hematoxylin and eosin. The presence of sialomucin was investigated using alcian blue staining at $\mathrm{pH} 2$ by routine procedure. Cells were also cultured on glass slides, washed with PBS, and fixed in cold acetone for immunocytochemical detection of the epithelial marker, keratin. To visualize the presence of specific antigens, the peroxidase-antiperoxidase (PAP) staining method was followed.

After preincubation with $10 \%$ normal rabbit serum, the slides were incubated overnight with a specific monoclonal antibody cocktail (clone AE1 and AE3 from Biogenex, Ramon, Calif.) at a $200 \times$ dilution. This antibody cocktail detects high molecular weight (basic) and low molecular weight (acidic) cytokeratins. After rinsing with PBS, the slides were incubated with a rabbit antimouse immunoglobulin serum (Dako, Glostrup, Denmark) at a $25 \times$ dilution. Subsequently, a mouse antiperoxidase monoclonal, to which peroxidase was coupled, was added (Sigma, Montesanto, St. Louis, Mo.) at a $200 \times$ dilution. The cells were stained with diaminobenzoic acid (DAB), to which $\mathrm{H}_{2} \mathrm{O}_{2}$ was added and sealed. As a positive control for cytokeratin staining, the colon carcinoma cell line HT-29 was used.

DNA isolation, microsatellite analysis, and chromosome number

Polymorphic microsatellite marker analysis was used to verify the derivation of the xenografts and cell lines and to confirm their tumor cell nature by loss of heterozygosity. DNA was isolated from cultured cells, frozen xenografts, and frozen patient normal and tumor tissue by means of standard proteinase $\mathrm{K}$ digestion and phenol/chloroform extraction.

Eight highly polymorphic microsatellite markers on chromosomes 14 and 16 were amplified using the polymerase chain reaction (PCR), as described by Trapman et al. [13]. Markers D14S67, D14S78, D14S1010, D14S1037, D16S265, D16S398, D16S503, and D16S512 were amplified in a $15-\mu l$ reaction volume (containing $1.5 \mathrm{mM} \mathrm{MgCl}, 0.02 \mathrm{mM}$ dATP, $0.2 \mathrm{mM}$ dGTP, $0.2 \mathrm{mM}$ dTTP, and $0.2 \mathrm{mM}$ dCTP, $0.8 \mu \mathrm{Ci} \alpha$-32P-dATP, $20 \mathrm{pmol}$ of each primer, and $0.2 \mathrm{U} \mathrm{Taq}$ polymerase, Promega). PCR was carried out under standard conditions. PCR products were size separated using electrophoresis in a $6 \%$ polyacrylamide gel. After drying, the gels were exposed overnight to X-ray film.

The chromosome number of the in vitro growing cell lines was determined using a standard procedure. In short, the cell cultures were treated overnight with colcemid, and the harvested cell suspensions underwent a hypotonic shock in $\mathrm{KCl}$. The cells were then fixed in methanol/acetic acid, and the metaphase spreads were stained with DAPI (4'-6'-diamidino-2-phenylindole). Chromosome number was determined by counting 10-20 well-spread metaphases.

\section{Results}

\section{Tumors}

Based on the macroscopic and microscopic examination of the resection specimens, the tumors around the GEJ were classified as Barrett-related $(n=16)$ or non-Barrett adenocarcinomas, both from gastric and esophageal origin. The presence or absence of Barrett's transformed mucosa adjacent to the tumors discriminated Barrett's from non-Barrett's adenocarcinomas, respectively. Of 16 Barrett's adenocarcinomas seven were classified as poorly differentiated, seven were moderately differentiated, and two were well-differentiated. Of the 54 non-Barrett adenocarcinomas 22 were undifferentiated, 30 were moderately differentiated, and two were well-differentiated (Table 1).

\section{Xenografting}

Primary adenocarcinomas of the GEJ (70 adenocarcinomas) and 17 lymph node metastases were xenografted to nude mice. This resulted in the initial growth of 3 tumors from 16 xenografts from Barrett adenocarcinomas and 19 tumors from 54 transplantations of non-Barrett adenocarcinomas. After transplantation of the 17 lymph node metastases ( 2 originating from Barrett tumors and 15 from non-Barrett carcinomas), six xenografts were obtained, all originating from gastric cardia carcinomas. Therefore, the total success rate of growing xenografts was $32 \%$. Repeated transplantations of xenografts resulted in the establishment of six long-term xenografts from primary tumors and three from metastases. One of these in vivo lines originated from a primary Barrett's adenocarcinoma. The lines were given the notation OAC (esophageal adenocarcinoma) of the primary tumor or of the metastasis, respectively, followed by the tumor number and the xenograft. The following lines were obtained from primary adenocarcinomas OACP33X, OACP47X, OACP56X, OACP58X, OACP67X, and OACP76X and from metastases OACM2.1X, OACM30X, and OACM53X.

Table 1 Xenografting adenocarcinomas of the gastro-esophageal junction. Xenograft take was compared with histological grade of the primary tumors or metastases. The data are expressed as the number of xenografts/number of primary tumors or metastases

\begin{tabular}{llcrl}
\hline Type & Undifferentiated & Moderately differentiated & Well-differentiated & Total take \\
\hline Barrett $n=16$ & $1 / 7$ & $2 / 7$ & $0 / 2$ & $3(18.7 \%)$ \\
Non-Barrett $n=54$ & $7 / 22$ & $10 / 30$ & $2 / 2$ & $19(35.3 \%)$ \\
Metastases $n=17$ & $2 / 9$ & $4 / 8$ & $0 / 0$ & $6(35.2 \%)$ \\
\hline
\end{tabular}


There was no strict correlation between the degree of differentiation and successful xenografting. Of the nine lines, seven and two originated from moderately differentiated and poorly differentiated tumors, respectively. The three cell lines established from metastases were derived from moderately differentiated tumors.

\section{In vitro culture}

Of the 70 primary GEJ adenocarcinomas and the 17 metastases, 34 and 9, respectively, were also cultured in vitro. Many of them became infected, and a number were overgrown by fibroblasts. Ultimately three long-term in vitro growing cell lines were established $(7 \%)$.

Two cell lines, i.e., OACP4 C and OACM4.1 C, derived from the same patient grew adherent in monolayer and were pleiomorphic, with epithelioid and fibroblastoid cells with cytoplasmic protrusions (Fig. 1A). In the cultures, several multinucleated giant cells (Fig. 1B) were observed.

The third cell line, OACM5.1 C, was derived from a lymph node metastasis from a patient suffering from a Barrett's adenocarcinoma. This cell line grew loosely attached to the culture flask and in multicellular floating spheroids. The cells were round or had a fibroblastoid morphology (Fig. 1C). These three in vitro cell lines appeared to be tumorigenic in nude mice and developed subcutaneous tumors within 6-8 weeks.

\section{Histology and immunocytochemistry}

The histology of all xenografts, including those formed by transplantation of cells from the three in vitro cell lines, completely resembled the histology of the primary tumor and metastatic derivatives resected from the patients. Figure 2A, B shows a primary differentiated tumor and the corresponding xenograft, and Fig. 2C, D shows the comparison of an undifferentiated primary tumor with the xenograft from the in vitro cell line. With the alcian blue staining, all xenografts appeared to harbor sialomucin-producing cells, as did the primary tumors. The established xenografts and in vitro cell lines were derived from invasive tumors. However, no invasion into the surrounding tissue of the subcutaneous xenografts was observed. All xenografts presented as encapsulated subcutaneous tumors. Variable cytoplasmic expression of cytokeratin was demonstrated in all three in vitro cell lines, confirming their epithelial nature (not shown).

\section{Microsatellite analysis and chromosome number}

To confirm the derivation of the xenografts and in vitro cell lines, their DNA was compared with the patient's tumor and normal DNA. With eight highly polymorphic
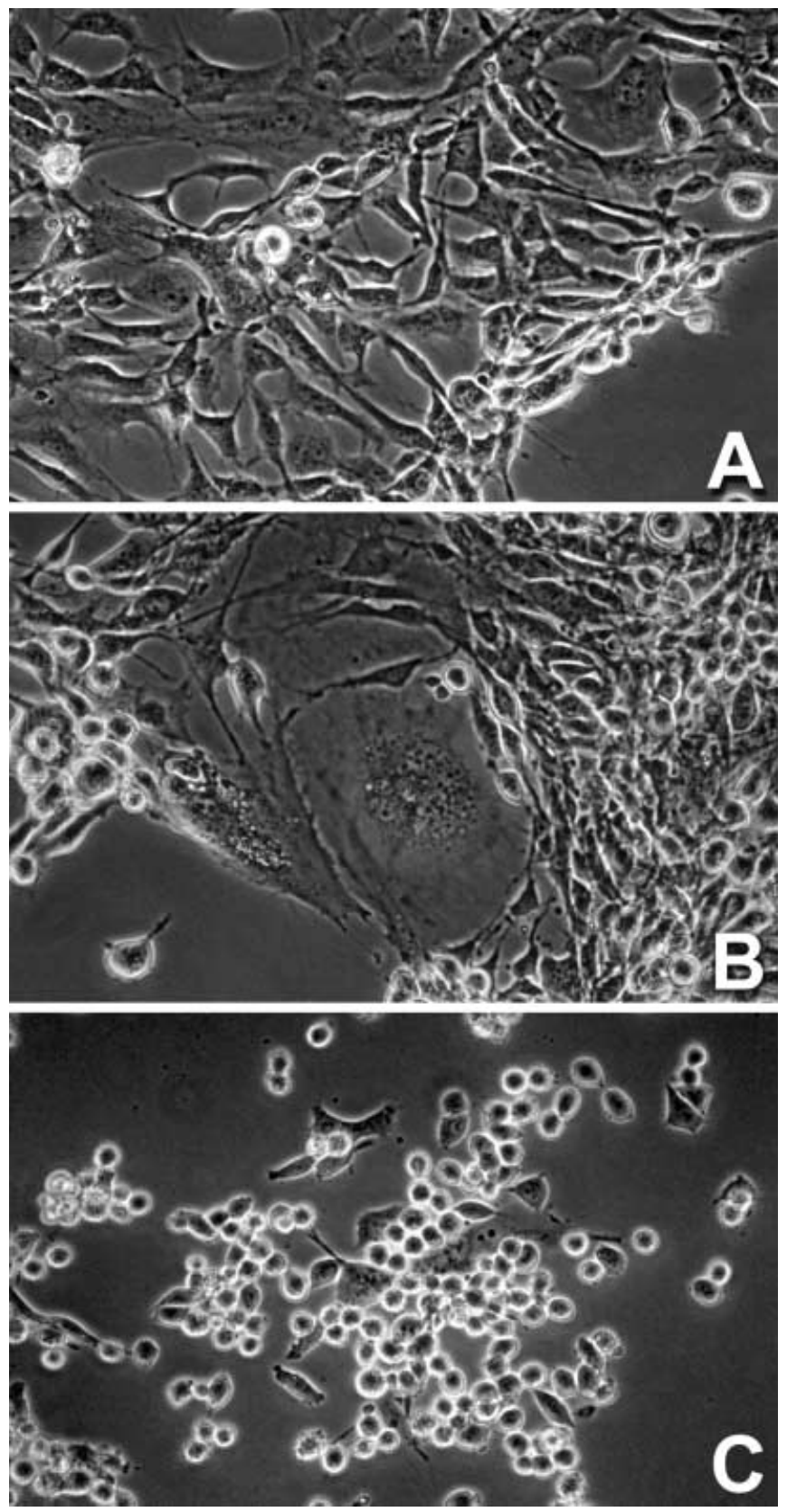

Fig. 1 Phase-contrast images of OACP4 C (A). Note the pleiomorphic nature and the multinucleate giant cells (B). OACM5.1 C formed multicellular spheroids $(\mathbf{C})$

microsatellite markers, all alleles in the xenografts and in vitro cell lines were present in the corresponding primary tumors and normal tissues (Fig. 3A, B). In addition, $\mathrm{LOH}$ was found with at least one of these markers in the xenografts and three cell lines. The LOH patterns were in all cases comparable with the LOH patterns found in the matched primary tumors or metastases (Fig. 3A, B).

All three in vitro cell lines appeared to be aneuploid. OACP4 C and OACM4.1 C had 53-57 and 52-65 chromosomes, respectively. OACM5.1 C was hypodiploid with 39-41 chromosomes. Further karyotypic character- 

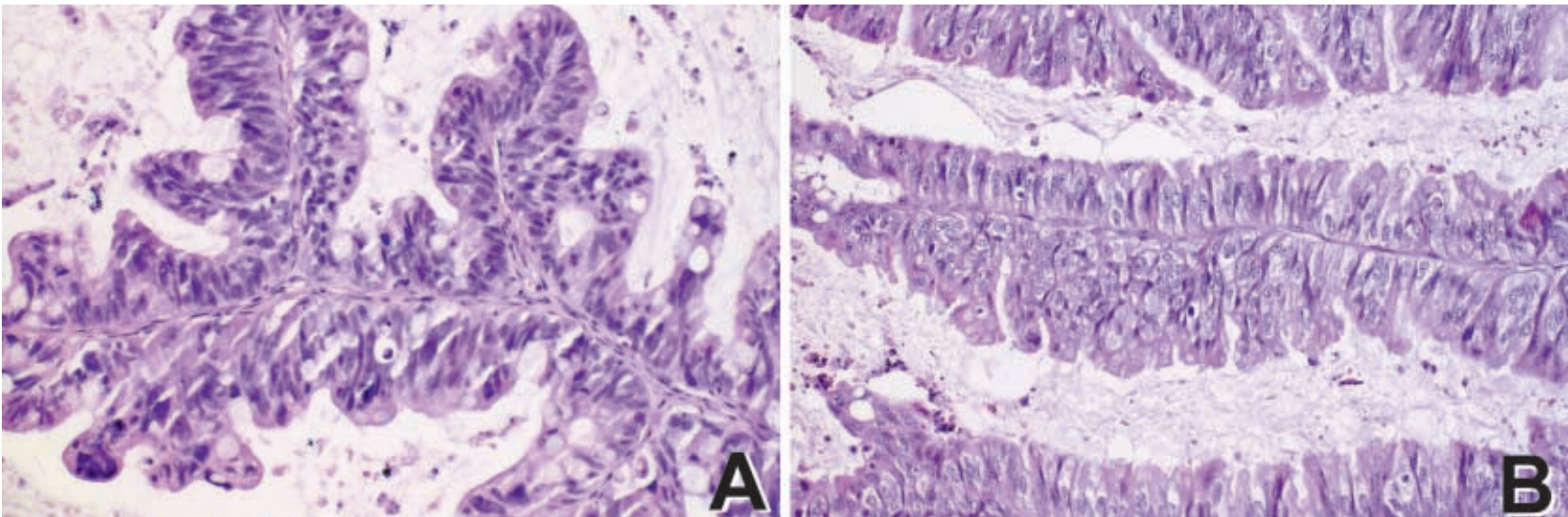

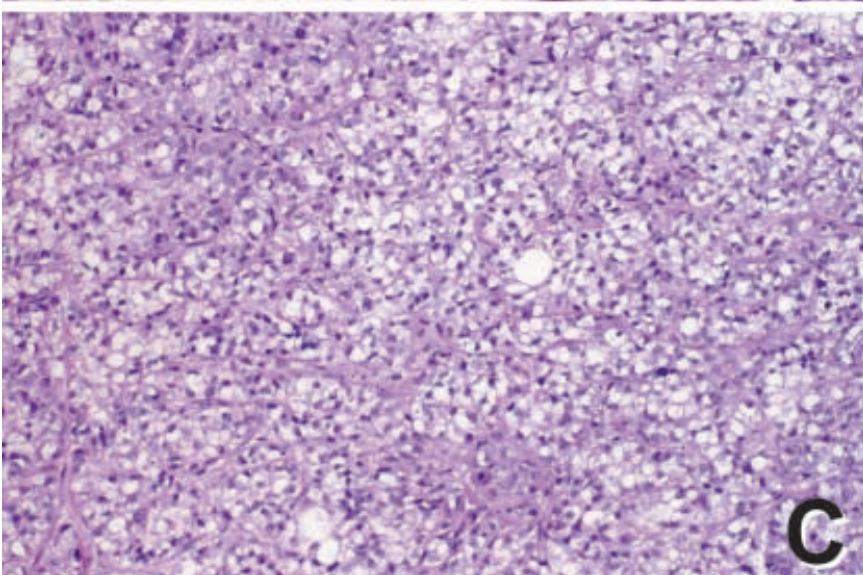

Fig. 2 Histology of differentiated xenograft OACP58X (A) compared with that of the primary tumor $(\mathbf{B})$. Comparison of the undifferentiated xenograft of the in vitro cell line OACM4.1 C (C) with the corresponding primary tumor (D)

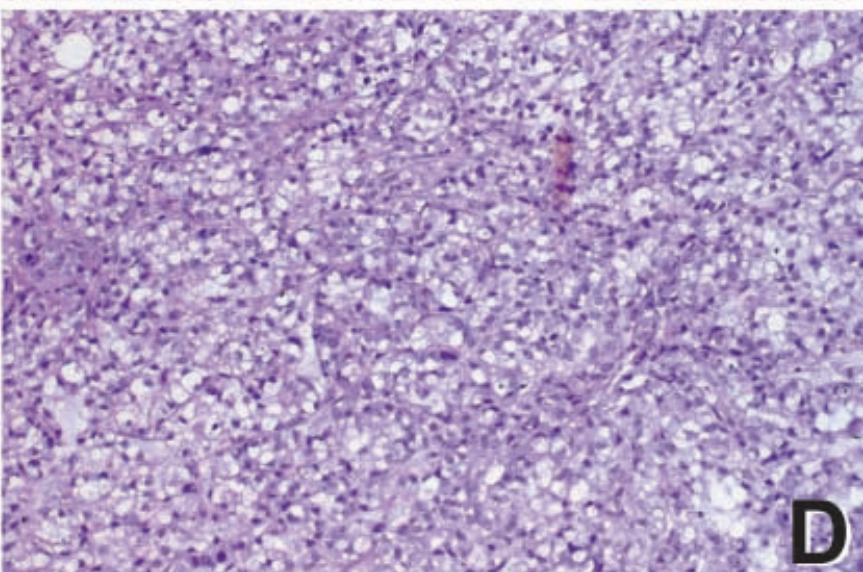

ization will be published as part of a separate report (Rosenberg et al., unpublished observations).

\section{Discussion}

In general, the success rate of xenografts from GEJ adenocarcinomas on nude mice is very reasonable, although long-term establishment of these xenografts was limited compared with that of other tumors [4]. The tumor growth does not correlate with the tumor grade of the tissue transplanted. Most lines were derived from moderately and not from poorly differentiated tumors. It is likely that the subcutaneous microenvironment or impaired vascularization may explain the many negative

Fig. 3 A Microsatellite analysis with polymorphic marker D14S1010 on in vitro primary tumor cell line OACP4 C (P4) and metastasis cell line OACM4.1 C (M4.1). The primary tumor (T) and normal DNA $(N)$ were from the same patient. The patient was heterozygous for this marker, and a complete loss of the upper allele (arrowhead) was observed in the cell lines. A partial loss was observed in the primary tumor. The upper allele in the primary tumor was most likely derived from normal human cells present in the tumor specimen. B Microsatellite analysis with polymorphic marker D14S1010 on metastasis xenograft (M53X, first passage), primary tumor $(T)$, and normal DNA $(N)$ from the same patient. The patient is heterozygous for this marker. A complete loss was observed in the xenograft, and a partial loss was observed in the primary tumor (arrowhead) 
cases. Alternatively, the sensitivity of tumor cells to the natural killer cells of nude mice may hamper their outgrowth. Orthotopic transplantation of the established cell lines to the cardia did not improve the outgrowth (unpublished results) despite the malignant nature [12] and the genetic instability of these tumors [7]. The 87 primary transplantations resulted in the initial growth of $28 \mathrm{xe}-$ nografts $(32 \%)$. After repeated retransplantations, only nine $(10 \%)$ xenografts could be established as permanent lines. There was no correlation with pathological criteria and long-term xenograft growth. LOH analyses revealed that already in the first passage xenografts, obtained 2-4 months after primary transplantation, no contaminating normal human cells were present in the tumors (Fig. 3B).

The xenografts were not contaminated with normal human stromal cells. Therefore, they are of value for comparative genomic hybridization [2, 13]. DNA from xenografts was also used for mapping of deletions on the long arm of chromosome 4 [10] and in studying E-cadherin and $\beta$-catenin mutations in GEJ adenocarcinomas $[15,17]$. The number of well-described permanent in vitro GEJ adenocarcinoma cell lines is limited. Altorki et al. [1] have reported the growth of three permanent cell lines (SK-GT-1, 4, and 5) from which one was derived from a Barrett's carcinoma. Rockett et al. [9] generated a series of tumor cell lines called JROECL 19, 33, 47, and 50. The cell line JROECL 33 originated also from a Barrett's adenocarcinoma. However, two lines, JROECL 47 and 50, proved to be subclones of the colon carcinoma cell line HCT 116 [16].

Palanca-Wessels et al. [8] established four permanent cell lines from Barrett's metaplastic epithelium, all of which already showed polyploidy, $\mathrm{LOH}$ of chromosome $9 \mathrm{p}$ and, in three of four cultures, loss of $17 \mathrm{p}$ and p53 mutations. More recently, a number of less well-characterized lines Seg-1, Flo-1, and Bic-1 were preliminarily reported in a study on the differential expression of heatshock proteins in Barrett's metaplasia and esophageal adenocarcinomas [11].

Our in vitro cell lines expressed cytokeratin, indicating their epithelial nature. All xenografts, also from the in vitro cell lines and from undifferentiated tumors, harbored sialomucin-containing cells, demonstrating their derivation from adenocarcinomas. It is obvious that the histology of the xenografts corresponded to that of the primary tumor. Also, when the cells of the permanent in vitro cell lines were transplanted to nude mice, they gave rise to tumors, which were histologically similar to the tumors from which they originated. However, all primary tumors were invasive, whereas none of the subcutaneous xenografts showed invasiveness. This is comparable with, for example, colorectal tumor cell lines which show no invasion after heterotopic transplantation but invasion is observed at the orthotopic site [14].

The microsatellite analysis of the primary tumor and the corresponding xenograft or cell line proves their common origin. All three in vitro cell lines were aneu- ploid, in agreement with reports that most GEJ have aberrant ploidy levels [5]. The chromosome numbers of cell lines OACP4 C and OACM4.1 C were in the same range, and this is consistent with numerous reports on comparable ploidy of paired primary tumors and metastases. Cell line OACM5.1 C had a hypodiploid karyotype. Although uncommon, hypodiploidy has been described in GEJ adenocarcinoma [6].

In conclusion, the results showed that GEJ adenocarcinoma cell lines growing in vivo and in vitro can be successfully established and histologically, immunocytochemically, and genetically resemble the tumors from which they originated. These xenografts and cell lines are a valuable source of homogeneous tumor tissue for further investigations.

Acknowledgements We thank Dr. C. Rosenberg, from Leiden University Medical Center, for chromosome number determinations and Mr. F. van der Panne for photographic work. This study was supported by a grant from the foundation "Gastrostart".

\section{References}

1. Altorki N, Schwartz GK, Blundell M, Davis BHM, Kelsen DP, Albino AP (1993) Characterization of cell lines established from human gastric-esophageal adenocarcinomas. Cancer 72: 649-657

2. Dekken van H, Geelen E, Dinjens WNM, Wijnhoven BPL, Tilanus HW, Tanke HJ, Rosenberg C (1999) Comparative genomic hybridization of cancer of the gastro-esophageal junction. Deletion of 14q31-32.1 discriminates between esophageal Barrett and gastric cardia adenocarcinomas. Cancer Res 59: $748-752$

3. El-Rifai W, Harper JC, Cummings OW, Hyytinen ER, Frierson HF Jr, Knuutila S, Powell SM (1998) Consistent genetic alterations in xenografts of proximal stomach and gastro-esophageal junction adenocarcinomas. Cancer Res 58:43-37

4. Fogh J, Fogh JM, Orfeo Th (1977) One hundred and twentyseven cultured human tumor cell lines producing tumors in nude mice. J Natl Cancer Inst 59:221-226

5. Gleeson CM, Sloan JM, McManus DT, Maxwell P, Arthur K, McGuigan JA, Ritchie AJ, Russell SEH (1998) Comparison of p53 and DNA content abnormalities in adenocarcinoma of the oesophagus and gastric cardia. Br J Cancer 77:277-286

6. Menke-Pluymers MBE, van Drunen E, Vissers KJ, Mulder AH, Tilanus HW, Hagemeijer A (1996) Cytogenetic analysis of Barrett's mucosa and adenocarcinoma of the distal esophagus and cardia. Cancer Genet Cytogenet 90:109-117

7. Montesano R, Holstein M, Hainant P (1996) Genetic alterations in esophageal cancer and their relevance to the etiology and pathogenesis; a review. Int. J Cancer 69:225-235

8. Palanca-Wessels MC, Barrett MT, Galipeau PC, Rohrer KL, Reid BJ, Rabinovitch PS (1998) Genetic analysis of long-term Barrett's esophagus epithelial cultures exhibiting cytogenetic and ploidy abnormalities. Gastroenterol 114:295-304

9. Rockett JC, Larkin K, Darnton SJ, Morris AG, Matthews HR (1997) Five established oesophageal carcinoma cell lines: phenotypic and immunological characterization. Br J Cancer 75: 258-263

10. Rumpel CA, Powell St M, Moskaluk Ch A (1999) Mapping of genetic deletions on the long arm of chromosome 4 in human esophageal adenocarcinomas. Am J Pathol 154:1329-1334

11. Soldes OS, Kuick RD, Thompson IA 2nd, Hughes SJ, Orringer MB, Iannettoni MD, Hanash SM, Beer DG (1999) Differential expression of Hsp27 in normal oesophagus, Barrett's metaplasia and oesophageal adenocarcinomas. Br J Cancer 79: 595-603 
12. Spechler SJ, Goyal RK (1986) Barrett's esophagus. N Engl J Med 315:362-371

13. Trapman J, Sleddens HFBM, van der Weiden MM, Dinjens WNM, Konig JJ, Schroder FH, Faber PW, Bosman FT (1994) Loss of heterozygosity of chromosome 8 microsatellite loci implicates a candidate tumor suppressor gene between loci D8S87 and D8S133 in human prostate cancer. Cancer Res 54:6061-6064

14. Vries de JE, Dinjens WNM, De Bruyne GK, Verspaget HW, van der Linden EPM, de Bru AP, Mareel MM, Bosman FT, ten Kate J (1995) In vivo and in vitro invasion in relation to phenotypic characteristics of human colorectal carcinoma cells. Br J Cancer 71:271-277
15. Wijnhoven BPL, de Both NJ, van Dekken H, Tilanus HW, Dinjens WNM (1999) E-cadherin gene mutations are rare in adenocarcinomas of the oesophagus. Br J Cancer 80:16521657

16. Wijnhoven BPL, Tilanus MGJ, Morris AG, Darnton SJ, Tilanus HW, Dinjens WNM (2000) Human oesophageal adenocarcinoma cell lines JROECL 47 and JROECL 50 are admixtures of the human colon carcinoma cell line HCT 116. Br J Cancer 82:1510-1512

17. Wijnhoven BPL, Nollet F, de Both NJ, Tilanus HW, Dinjens WNM (2000) Genetic alterations involving exon 3 of the $\beta$-catenin gene do not play a role in adenocarcinomas of the esophagus. Int J Cancer 86:533-537 